\title{
Age-dependent systemic DNA damage in early Type 2 Diabetes mellitus
}

\author{
Dinko Rogulj1凶, Ismail El Aklouk², Paško Konjevoda ${ }^{3}$, Spomenka Ljubić4, Mirjana Pibernik \\ Okanović ${ }^{4}$, Ante Barbir ${ }^{5}$, Marijana Luburićs, Maja Radman ${ }^{6}$, Ninoslav Budinski ${ }^{7}$ and Marijana \\ Vučić Lovrenčić 8
}

\begin{abstract}
'Department of Internal Medicine, General Hospital Brežice, Slovenia; ${ }^{2}$ General Hospital Varaždin, Department for extending and palliative care Novi Marof, Croatia; ${ }^{2}$ NMR Centre, Institute Rudjer Bošković, Zagreb, Croatia; ${ }^{4}$ Vuk Vrhovac University Clinic for Diabetes, Endocrinology and Metabolic Diseases, University Hospital Merkur, Zagreb, Croatia; 5 Polyclinic Sunce, Zagreb, Croatia; ${ }^{6}$ Department of Internal Medicine, University Hospital Centre Split, Split, Croatia; 'Department of Internal Medicine, University Hospital Sveti Duh, Zagreb, Croatia; ${ }^{8 D e p a r t m e n t ~ o f ~ L a b o r a t o r y ~}$ Medicine, Scientific Research Unit, University Hospital Merkur, Zagreb, Croatia
\end{abstract}

Oxidative stress, capable of eliciting damage to various biomolecules including DNA, is a recognized component of diabetes mellitus and its complications. Metabolic syndrome (MetS) is associated with the development of type 2 diabetes mellitus (T2DM), as well as other unfavorable outcomes. The aim of this study was to elucidate the role of oxidative stress in the development of T2DM, by investigating association of oxidative DNA damage with metabolic parameters in subjects with MetS and early T2DM. Selected anthropometric and biochemical parameters of MetS, inflammation and oxidative DNA damage: body mass index (BMI), fatty liver index (FLI), waist circumference (WC), total cholesterol, HDL and LDL-cholesterol, gamma-glutamyl transpeptidase (GGT), uric acid, C-reactive protein (CRP), total leukocyte/neutrophil count, and urinary 8-hidroxy-deoxyguanosine (u-8-OHdG) were assessed in male subjects with MetS and both younger ( $\leq 55$ years) and older ( $>55$ years) subjects with T2DM of short duration without complications. BMI, FLI, WC, total and LDL-cholesterol and uric acid were higher, while the u-8-OHdG was lower in MetS group, when compared to older T2DM subjects. None of these parameters were different neither between MetS and younger T2DM, nor between two sub-groups of subjects with T2DM. Values of CRP, HDL-cholesterol, triglycerides, GGT, leukocytes and neutrophils were not different between all examined groups of subjects. Higher 8-OHdG in older subjects with T2DM suggests that both aging process and diabetes could contribute to the development of DNA damage. Oxidative DNA damage cannot serve as an universal early marker of T2DM.

Key words: metabolic syndrome, type 2 diabetes mellitus, DNA damage, urinary $8-\mathrm{OHdG}$

Received: 05 May, 2016; revised: 12 July, 2016; accepted: 06 October, 2016; available on-line: 30 March, 2017

e-mail: Dinko.Rogulj@xnet.hr

Abbreviations: MetS, metabolic syndrome; OS, oxidative stress; T2DM, type 2 diabetes mellitus; BMI, body mass index; FLI, fatty liver index; WC, waist circumference; 8-OHdG, 8-hydroxy-2'-deoxyguanosine; ROS, reactive oxygen species; $\mathrm{HDL}$, high density lipoprotein; LDL, low density lipoprotein; GGT, gamma glutamyl transpeptidase

\section{INTRODUCTION}

Although oxidative stress (OS) is considered to be a recognized component of metabolic syndrome (MetS), there are many unanswered questions about its role in the pathogenesis and progression of the associated complications (Roberts \& Sindhu, 2009; Rochette et al., 2014). Type 2 diabetes mellitus (T2DM) is one of the most prevalent complications of metabolic syndrome, as well as the condition of elevated oxidative stress, resulting from both increased production of reactive oxygen species (ROS) and disturbed antioxidant defence system (Rochette et al., 2014).

ROS are intrinsically generated as by-products of normal aerobic metabolism and inflammatory/immune response to various challenges (Valko et al., 2007). Exposure to the external sources of ROS, such as radiation, environmental pollutants and toxins, also contributes to oxidative stress capable of inflicting irreversible damage to biomolecules (4). The increased production of ROS activates various mechanisms of defence and repair of oxidative damage (Valko et al., 2007, Halliwell \& Gutteridge, 2015). Unreparably damaged proteins and lipids can be replaced by de novo synthesis, as long as their coding DNA is intact. However, oxidative damage to DNA, if not repaired, may seriously compromise the cell-function (Erol, 2010; Halliwell \& Gutteridge, 2015).

The role of oxidatively modified DNA has been implicated in a wide range of human pathology: cancer, diabetes, arteriosclerosis and neurodegenerative diseases being among the most prominent examples (Jackson \& Bartek, 2009). DNA integrity is protected from oxidative damage by a multitude of mechanisms, including structure-specific features, assembly with histones and specific localization within the cell-core. Apart from this, the cell is equipped with a variety of effective repairing mechanisms, such as base excision repair and nucletoide excision, dedicated to coping with oxidative damage to DNA (Jackson \& Bartek, 2009). In order to prevent DNA damage, oxidized nucleobases are excised and eliminated from the cellular pool.

In comparison to other bases, due to the lowest redox potential, guanine is the most sensitive to oxidation by reactive oxygen species (ROS) (Poulsen et al., 2014). 8-hydroxy-2'-deoxyguanosine (8-OHdG) and its 8-oxotautomer (8-oxo-7,8-dihydro-2'-deoxyguanosine, abbreviated 8-oxodG), a nucleoside generated by the guanine oxidation, has been so far the most extensively studied biomarkers of oxidative DNA damage in humans. Urinary $8-\mathrm{OHdG}$ is generally considered to be a reliable and non-invasive marker of general intracellular oxidative stress, provided that confounding biological and analyti- 
cal variations have been appropriately adressed (Loft et al, 2012; Poulsen et al., 2014).

Evidence collected so far on the oxidative damage to DNA in subjects with metabolic syndrome and diabetes mellitus provided conflicting results. Either elevated, unchanged or decreased levels of oxidative DNA were found in MetS (Demirbag et al., 2006; Song et al., 2007; Milić et al., 2013), but these studies investigated different biomarkers of DNA oxidation in diverse study-populations with various degree and duration of MetS. Thus, the question of whether oxidative damage to DNA precedes, follows or develops simultaneously with metabolic syndrome remained unanswered.

As regards diabetes, elevated u-8-OHdG levelwas reported in both T1DM and T2DM patients with poorly regulated glycaemia, and its predictive value regarding micro-and macrovascular complications was suggested (Broedbaek et al., 2011). However, evidence on the oxidative DNA damage in T2DM patients with a short duration of disease and the absence of complications is scarce, and its possible association with the progression of T2DM from MetS has not been adressed so far.

In this study, we aimed to assess oxidative DNA damage, as measured by u-8-OHdG in subjects with recently diagnosed type 2 diabetes mellitus (T2DM), in comparison to otherwise healthy individuals with metabolic syndrome (MetS), in order to test the hypothesis that oxidative DNA damage could be a marker of progression of T2DM from MetS.

\section{SUBJECTS AND METHODS}

Subjects. The study was conducted in Zagreb, Croatia, during the years 2012-2013. The subjects with MetS were 51 consecutively recruited Caucasian non-smoker males (age range: 43-50 years) who had annual medical checkup in an internal medicine outpatient department. Metabolic syndrome was diagnosed according to the National Cholesterol 101 Education Program-Adult Treatment Panel III (NCEP-ATP III) guidelines (Expert Panel on Detection, Evaluation, and Treatment of High Blood Cholesterol in Adults, 2001). The exclusion criteria for MetS group were: previous diagnose of diabetes mellitus, heart failure, liver and kidney disease, malignancies, autoimmune disorders as well as recent surgery and acute inflammation/infection.

Patients with T2DM (N=55) were recruited at the diabetes outpatient department among male non-smokers at their regular annual examination. The inclusion criteria were: age $<62$ years, male gender, diabetes duration $<5$ years, $\mathrm{HbA} 1 \mathrm{c}<8.0 \%(63.9 \mathrm{mmol} / \mathrm{mol})$, normal albumin excretion rate (expressed as albumin/creatinine ratio $<3$ $\mathrm{mg} / \mathrm{mmol}$ ) and the absence of micro-and macro-vascular complications at physical examination. Patients with a history of cardiovascular incidents, heart failure, liver and kidney disease, recent surgery, acute inflammation/ infection, malignancy or autoimmune diseases were not included in this study.

Methods. Blood was drawn and spot urine-samples collected from all subjects in the morning, after an overnight fasting (at least 8 hours). Routine biochemistry and hematology work-up was carried out within 8 hours and urine samples for u-8-OHdG measurement were aliquoted and frozen $\left(-70^{\circ} \mathrm{C}\right)$ until analysed (within 6 months from collection). Laboratory analyses were performed in the clinical laboratory acredited according to a recognized international standard „ISO 15189:2012-Medical laboratories - Requirements for quality and competence“"

Table 1. Variables analyzed in the non-diabetic MetS and two groups of diabetic subjects $-\leq 55$ years and $>55$ years. Data are presented as median and interquartile range (in parentheses).

\begin{tabular}{|c|c|c|c|c|c|c|c|}
\hline Variable & $\begin{array}{c}\text { Group1 } \\
\text { MetS } \\
(n=51)\end{array}$ & $\begin{array}{c}\text { Group } 2 \\
\text { T2DM } \leq 55 \text { years } \\
(\mathrm{n}=22)\end{array}$ & $\begin{array}{c}\text { Group } 3 \\
\text { T2DM }>55 \text { years } \\
(n=33)\end{array}$ & $\begin{array}{c}P \text {-value } \\
\text { Kruskal-Wallis } \\
\text { test }\end{array}$ & $\begin{array}{c}P \text {-value }{ }^{1} \\
\text { Group } 1 \text { vs. } \\
\text { Group } 2 \\
\end{array}$ & $\begin{array}{c}P \text {-value } 1 \\
\text { Group } 1 \text { vs. } \\
\text { Group } 3\end{array}$ & $\begin{array}{c}P \text {-value }{ }^{1} \\
\text { Group } 2 \text { vs. } \\
\text { Group } 3 \\
\end{array}$ \\
\hline Age (years) & $47(43-50)$ & $50(46-53)$ & $59(56-61)$ & $<0.001$ & 0.631 & $<0.001$ & $<0.001$ \\
\hline $\begin{array}{l}\text { Urinary 8-OHdg ( } \mu \mathrm{g} / \\
\text { mmol creatinine) }\end{array}$ & $0.42(0.15-0.90)$ & $0.69(0.58-0.86)$ & $0.88(0.69-1.05)$ & 0.009 & 0.637 & 0.006 & 0.529 \\
\hline Uric acid ( $\mu \mathrm{mol} / \mathrm{L})$ & $403(351-459)$ & $373(280-408)$ & $334(293-377)$ & 0.001 & 0.084 & 0.001 & 1.000 \\
\hline GGT (U/L) & $42(30-73)$ & $47(28-65)$ & $30(23-63.5)$ & 0.118 & 1.000 & 0.132 & 0.471 \\
\hline $\begin{array}{l}\text { Total cholesterol } \\
(\mathrm{mmol} / \mathrm{L})\end{array}$ & $5.8(5.1-6.5)$ & $5.5(4.6-6.0)$ & $4.7(3.9-5.6)$ & 0.002 & 0.536 & 0.001 & 0.307 \\
\hline $\begin{array}{l}\text { HDL cholesterol } \\
(\mathrm{mmol} / \mathrm{L})\end{array}$ & $1.17(1.06-1.38)$ & $1.05(0.94-1.30)$ & $1.14(0.92-1.31)$ & 0.209 & 0.288 & 0.775 & 1.000 \\
\hline $\begin{array}{l}\text { LDL cholesterol } \\
(\mathrm{mmol} / \mathrm{L})\end{array}$ & $3.60(3.20-4.50)$ & $3.05(2.51-4.11)$ & $2.69(1.91-3.22)$ & $<0.001$ & 0.273 & $<0.001$ & 0.409 \\
\hline $\begin{array}{l}\text { Triglycerides } \\
\text { (mmol/L) }\end{array}$ & $2.23(1.69-3.51)$ & $2.92(1.48-4.80)$ & $2.05(1.37-2.85)$ & 0.065 & 0.753 & 0.385 & 0.065 \\
\hline CRP $(\mathrm{mg} / \mathrm{L})$ & $2.3(1.2-3.8)$ & $2.5(0.8-4.9)$ & $1.5(0.8-3.1)$ & 0.211 & 1.000 & 0.253 & 0.739 \\
\hline Leukocytes (109/L) & $6.7(6.0-8.1)$ & $7.0(6.4-7.6)$ & $7.5(5.5-8.4)$ & 1.000 & 1.000 & 1.000 & 1.000 \\
\hline Neutrophils $\left(10^{9} / \mathrm{L}\right)$ & $3.7(2.8-4.7)$ & $3.8(3.3-4.3)$ & $4.3(3.2-4.9)$ & 0.362 & 1.000 & 0.464 & 1.000 \\
\hline Body mass index & $31.4(30.0-34.8)$ & $32.0(29.3-32.9)$ & $29.9(26.9-32.8)$ & 0.021 & 0.537 & 0.018 & 0.251 \\
\hline Fatty liver index & $92.2(80.8-96.8)$ & $91.5(78.0-95.0)$ & $78(50.0-89.0)$ & 0.003 & 1.000 & 0.002 & 0.080 \\
\hline $\begin{array}{l}\text { Waist circumference } \\
(\mathrm{cm})\end{array}$ & $108(104-116)$ & $106.5(101-113)$ & $101.66(97-105.5)$ & $<0.001$ & 0.373 & 0.002 & 0.061 \\
\hline $\mathrm{HbA} 1 \mathrm{c}(\mathrm{mmol} / \mathrm{mol})^{2}$ & & $53.0(44.0-59.0)$ & $56.0(49.0-66.0)$ & & & & 0.230 \\
\hline
\end{tabular}

MetS=metabolic syndrome, T2DM=type 2 diabetes mellitus, GGT=gamma-glutamyl transpeptidase CRP=C-reactive protein ${ }^{1}$ Mann-Whitney $\mathrm{U}$-test with Bonferonni correction for multiple comparison. ${ }^{2} \mathrm{HbA} 1 \mathrm{c}$ was not measured in MetS group 
Fatty liver index (FLI) was calculated with the formula proposed by Bedogni et al. (Bedogni et al., 2006).

U-8-OHdG was measured by the competitive ELISA-method (New 8-OHdG Check, Japan Institute for the Control of Ageing, JaiCA, Shizuoka, Japan), with declared assay-range of $0.5-200 \mathrm{ng} / \mathrm{mL}$ and improved specificity (Evans et al., 2008). On the day of analysis, frozen urine samples were thawed in a water-bath $\left(37^{\circ} \mathrm{C}\right)$, vortexed, centrifuged $(10 \mathrm{~min}, 3000 \mathrm{rpm})$ and u-8-OHdG assayed immediately according to the manufacurer's instructions. Urinary creatinine was measured in the same samples with a compensated colorimetric Jaffe procedure (AU680 Analyser, Beckman Coulter, Brea, USA). Results were normalized to the creatinine concentration by the formula:

$\mathrm{u}-8-\mathrm{OHdG} / \mathrm{creatinine}(\mathrm{mg} / \mathrm{mmol})=\mathrm{u}-8-\mathrm{OHdG}(\mathrm{mg} / \mathrm{L}) /$ $\mathrm{u}$-creatinine $(\mathrm{mmol} / \mathrm{L})$

Statistical analysis. Statistical testing was based on Kruskal-Wallis and Mann-Whitney U-test with Bonferroni correction for multiple comparison. All applied procedures were two-tailed. The differences discussed in this paper were considered significant at the $p<0.05$
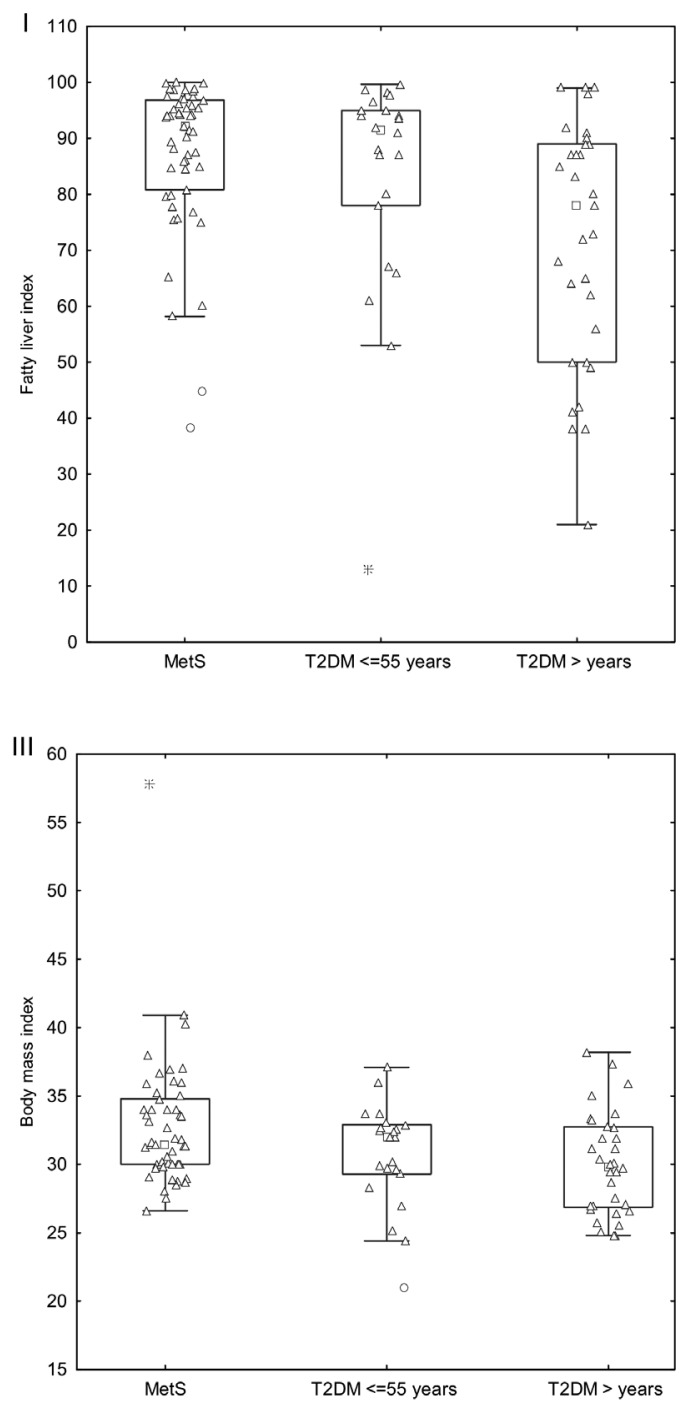

level. Statistica for Windows was used for data analysis and plotting (StatSoft, Inc. (2007). STATISTICA (data analysis software system), version 8.0. Tulsa, Oklahoma, USA. www.statsoft.com).

Ethical aspects. The study was approved by the institutional Ethics Committee. A written informed consent was obtained from all the participants.

\section{RESULTS}

The results of the measured parameters are presented in Table 1. Data are presented as medians and interquartile range (first quartile vs. third quartile), and plotted using box-and-whisker method. Because the T2DM subjects were overall older than those with MetS, we divided T2DM subjects into two sub-groups: first sub-group with subjects 55 years old and younger $(\mathrm{T} 2 \mathrm{DM} \leq 55)$ and second sub-group with subjects older than 55 years $(\mathrm{T} 2 \mathrm{DM}>55)$.

The level of serum uric acid, total cholesterol, LDLcholesterol, BMI, WC and FLI were significantly higher in MetS group, compared to T2DM $>55$ group. No
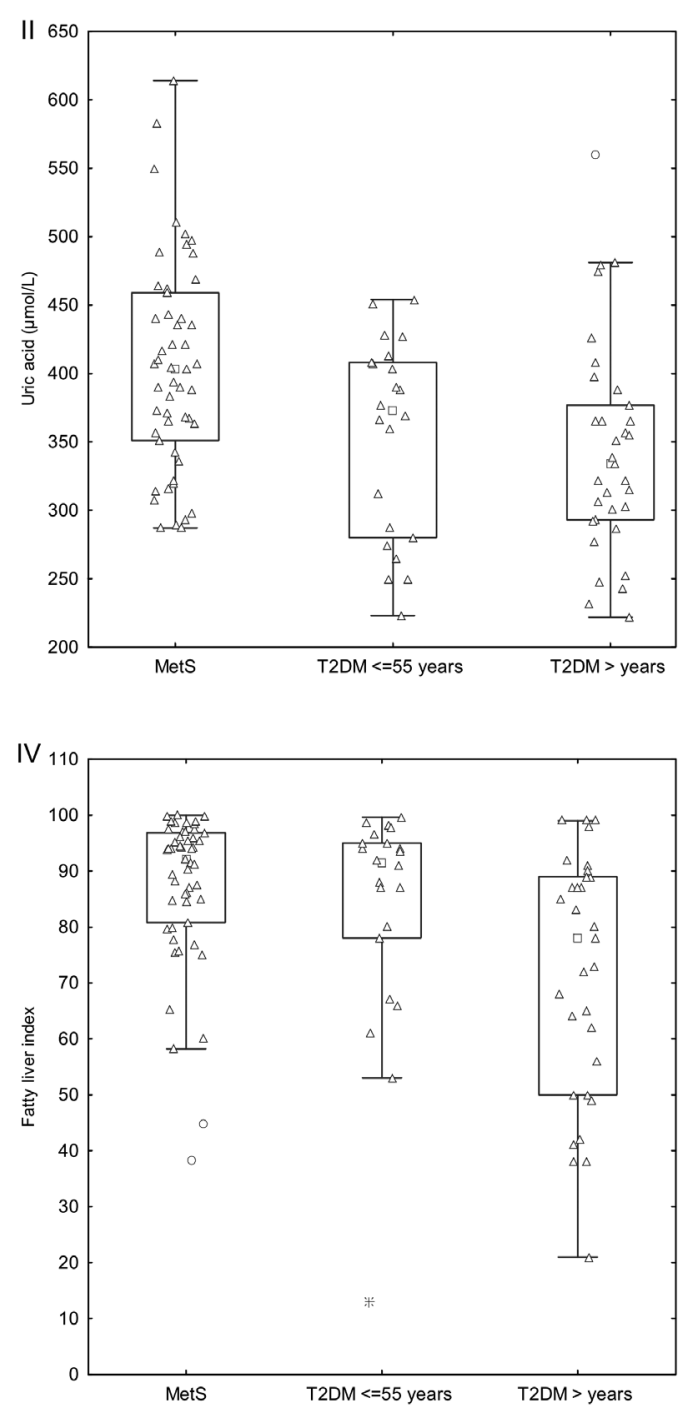

Figure 1. The difference in metabolic parameters between three groups of subjects:

(I) The waist circumference $(p=0.001)$, (II) serum uric acid $(p=0.001)$, (III) body mass index $(p=0.021)$, and (IV) fatty liver index ( $p=0.003$ ) of the MetS group, group of T2DM subjects $\leq 55$ years and group of T2DM subjects $>55$ years. Data are presented as box-and-whisker plots. The presented parameters were higher in MetS group, compared to T2DM $>55$ years group. 


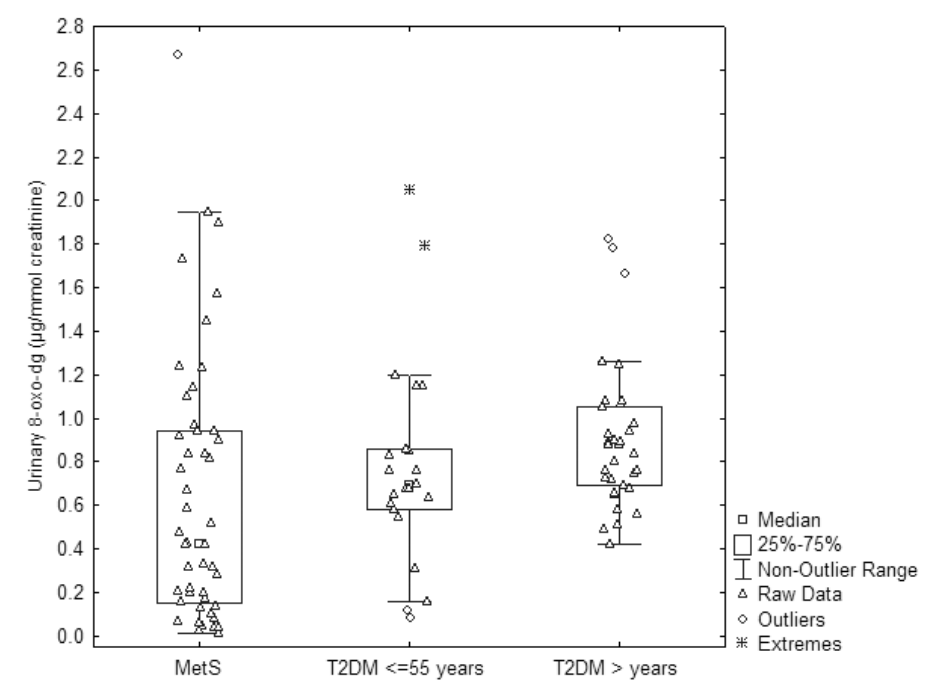

Figure 2. The level of u-8-OHdG of the MetS group, group of T2DM subjects $\leq 55$ years and group of T2DM subjects $>55$ years.

Data are presented as box-and-whisker plots. The level of u-8-OHdG was higher T2DM $>55$ years group, compared to MetS group. $p=0.009$; Kruskal-Wallis test.

significant difference in these parameters was observed between MetS and $\mathrm{T} 2 \mathrm{DM} \leq 55$, and $\mathrm{T} 2 \mathrm{DM}>55$ and $\mathrm{T} 2 \mathrm{DM} \leq 55$, respectively. Figure 1 shows $\mathrm{WC}$, uric acid, BMI and FLI values in the three groups of study subjects.

Other parameters (gamma-glutamyl transpeptidaseGGT, leukocyte count, neutrophil count, CRP) did not differ between all three groups, as did not diabetes duration and $\mathrm{HbA}_{1 \mathrm{c}}$ between $\mathrm{T} 2 \mathrm{DM} \leq 55$ years and T2DM $>55$ years subjects (Table 1 ).

The normalized levels of $8-\mathrm{OHdG} /$ creatinine were higher only in subjects with $\mathrm{T} 2 \mathrm{DM}>55$ years compared to those with MetS, while no difference was found when compared to $\mathrm{T} 2 \mathrm{DM} \leq 55$ years and between $\mathrm{T} 2 \mathrm{DM}$ subgroups, respectively (presented as box-whisker plot, Fig. 2).

\section{DISCUSSION}

Our study, conducted in a complication-free cohort of type 2 diabetic patients, revealed an age-dependent increase in $\mathrm{u}-8-\mathrm{OHdG}$ when compared to subjects with metabolic syndrome. This is consistent with our previous research, where no increase of DNA-damage on systemic level between younger subjects with MetS and healthy non-MetS controls was demonstrated (Milić et al., 2013).

The systemic level of OS increases with age (Soares et al., 2014) and DM (Broedbaek et al., 2011). Also, both T2DM (Blasiak et al., 2004) and older age (Loft et al., 2012; Soares et al., 2014) were identified as factors associated with impaired ability for repairing DNA from oxidative damage. In general, increased DNA damage is associated with older age, according to majority of, but not to all studies (Soares et al., 2014).

The reason for the inconsistent results could be heterogeneity of study populations regarding gender, age, stage of illness, presence of complications, as well as analytical and statistical methodology. Majority of studies reporting on a greater DNA damage in MetS and T2DM were done with subjects of both genders (Song et al., 2007; Broedbaek et al., 2011). Bukhari et al recently reported on both gender and age as significant determinants of the level of DNA damage in diabetic sub- jects (Bukhari et al., 2015), while Løhr et al found association of oxidative DNA damage with age in women, but not in men (Løhr et al., 2015). This association however, disappeared in multivariate models, and the authors concluded that relationship between DNA damage and age appeared to be mediated by age-related increases in metabolic risk factors.

$\mathrm{Li}$ and coworkers (2013) recently reported on an age-dependent increase in markers of oxidative DNA damage in diabetic animals. To the best of our knowledge, this is the first study addressing the issue of oxidative DNA damage at an early stage of T2DM in patients without micro- and macrovascular complications. It is plausible to speculate that the greater DNA damage in older T2DM subjects could be a consequence of older age and weaker antioxidative mechanisms, while younger T2DM subjects may maintain sufficient level of protective mechanisms towards DNA damage caused by factors associated with ageing and/or T2DM. Even though diabetes duration was not different between younger and older T2DM subjects, long period of undiagnosed asymptomatic illness is not uncommon in diabetes (IDF Diabetes Atlas, 2015). Thus, possible longer exposure to hyperglycaemia in older T2DM subjects should not be entirely ruled out as the reason for greater DNA damage. However, the same vagueness might equally be expected in a younger population of T2DM. Furthermore, lower FLI and WC in older T2DM subjects, implicate rather later onset of diabetes, possibly due to healthier eating and lifestyle habits with a consequence of decreased amount of adipose tissue.

Interestingly, although older subjects with T2DM had greater oxidative DNA damage, neither of the paremeters of OS and inflammation, which are recognized components of MetS, was higher compared to the other two groups. The uric acid level was higher in subjects with MetS, compared to older T2DM subjects. Uric acid is both marker of MetS and OS, since higher levels of uric acid are associated with cardiovascular diseases and generation of uric acid by xanthin-oxidoreductase is associated with production of ROS (Feig et al., 2008). Higher level of uric acid is linked with greater amount of abdominal adipose tissue (Takahashi et al., 1997) and our MetS subjects had greater WC and BMI. The role of uric acid in OS is contradictory; it is considered as an antioxidant by some authors, as the scavenger of ROS, whereas in other circumstances, such as atherosclerotic and prooxidant environment, it exhibits prooxidant properties (Hayden \& Tyagi, 2004).

While higher level of urates in might implicate an increased oxidative stress in MetS, the complex nature of OS, with many intertwining factors, precludes simple conclusions based on an isolated parameter differences (Bashan et al., 2009). On the other hand, lower u-8-OH$\mathrm{dG}$ in MetS may be associated with the maintained protective antioxidant machinery, whereby uric acid was recently evidenced to play an important role in vivo (Vučić et al., 2015).

Similar as in the study of Al Aubaidy \& Jelinek (Al Aubaidy \& Jelinek, 2011), the LDL level was lower in patients with T2DM, which probably resulted as a consequence of preventive treatment of T2DM subjects 
with statins. Neither of our MetS subjects received treatment with statins at the time of the study.

Despite lower risk factors (BMI, WC, FLI, uric acid level), older T2DM subjects had higher level of u-8-OH$\mathrm{dG}$, implicating age and possibly hyperglycaemia, rather than factors generally associated with MetS (e.g. quantity of adipose tissue, FLI) as key-determinants of DNA damage in diabetes. In contrast with our results, Rytter and al. found BMI and WC to be significantly associated with higher level of oxidative DNA damage, but lacked to find association of DNA damage with glycaemic control (Rytter et al., 2009). Other authors found association of DNA damage with glycemic control (Dincer et al., 2002; Brodbaek et al., 2006; ). We found no relationship between u-8-OHdG and level of glycaemia in diabetic subjects, probably due to the study design. Diabetic patients enrolled for our study had fair glycaemic control and there was no difference in HbA1c between older and younger T2DM subjects (Table 1).

Our study had several limitations. In order to ensure homogeneity of population, and avoid gender-associated differences in MetS, we decided to investigate only male subjects. Also, we did not examine DNA damage in subjects with MetS older than 55 years. T2DM pateints were regularly treated, educated and followed-up in outpatient diabetological department, which was not the case with MetS subjects, who were on a single medical checkup. Differences in subjects handling may influenced anthropometric measures, particularly WC and BMI. A lack of non-MetS, non-T2DM control group may be considered as another limitation, however the aim of our study was to test the hypothesis that oxidative DNA damage could be a marker of progression of T2DM from MetS, and the differences between healthy and diabetic, as well as MetS subjects have already been evidenced. Finally, cross-sectional design of the study did not allow an insight in the temporal relationship between MetS, T2DM and oxidative DNA damage.

\section{CONCLUSION}

According to the results of our study, T2DM of short duration and fair glycaemic control in younger patients is not associated with an increased oxidative DNA damage, when compared to age-matched subjects with MetS. Thus, DNA damage could not serve as a marker for early stage of T2DM. Significantly higher u-8-OHdG in older patients with T2DM was found, but no link to the specific biochemical and anthropometric indices of MetS was determined.

Inspite of the limitations, our study, conducted in a complication-free cohort of T2DM diabetes of short duration, for the first time revealed an age-dependent increase in u-8-OHdG when compared to subjects with metabolic syndrome, suggesting that both aging process and diabetes could contribute to the development of oxidative DNA-damage. Further research is needed to elucidate the role of oxidative DNA damage in the progression of diabetes and evaluate possible interventions towards preventing its detrimental consequences and improving patient outcomes.

\section{Acknowledgements}

We thank prof. S. Gamulin for proposing the initial idea for the study, J. Vučkovic, $\mathrm{MD}, \mathrm{PhD}$ for the advices and laboratory personnel for the help in the laboratory tests.

\section{REFERENCES}

Al Aubaidy H, Jelinek HF (2011) Oxidative DNA damage and obesity in type 2 diabetes mellitus. Eur J Endocrinol 164: 899-904. http:// www.infekt.ch/content/uploads/2013/11/jc_september11_kreiner. pdf

Bashan N, Kovsan J, Kachko I, Ovadia H, Rudich A (2009) Positive and negative regulation of insulin signaling by reactive oxygen and nitrogen species. Physiol Rev 89: 27-71. http://www.ncbi.nlm.nih. gov/pubmed/19126754

Bedogni G, Bellentani S, Miglioli L, Masutti F, Passalacqua M, Castiglione A, Tiribelli C (2006) The Fatty Liver Index: a simple and accurate predictor of hepatic steatosis in the general population. BMC Gastroenterol 6: 33. http://www.ncbi.nlm.nih.gov/pmc/articles/ PMC1636651/

Blasiak J, Arabski M, Krupa R, Wozniak K, Zadrozny M, Kasznicki J, Zurawska M, Drzewoski J (2004) DNA damage and repair in type 2 diabetes mellitus. Mutat Res 554: 297-304

Broedbaek K, Weimann A, Stovgaard ES, Poulsen HE (2011) Urinary 8-oxo-7,8-dihydro-2'-deoxyguanosine as a biomarker in type 2 diabetes. Free Radic Biol Med 51: 1473-1479

Bukhari SA, Naqvi SA, Nagra SA, Anjum F, Javed S, Farooq M (2015) Assessing of oxidative stress related parameters. Pak J Pharm Sci 28: 483-491

Demirbag R, Yilmaz R, Gur M, Celik H, Guzel S, Selek S Kocyigit A (2006) DNA damage in metabolic syndrome and its association with antioxidative and oxidative measurements Int J Clin Pract 60: 1187-1193. http://www.ncbi.nlm.nih.gov/pubmed/16981963

Dincer Y, Akcay T, Alademir Z, Seyisoglu H, Ertungalp E (2002). Assessment of DNA base oxidation and glutathione level in patients with type 2 diabetes. Mutat Res 505: 75-81. http://www.ncbi.nlm. nih.gov/pubmed/12175907

Erol A (2010) Systemic DNA damage response and metabolic syndrome as a premalignant state. Curr Mol Med 10: 321-334. http://www.ingentaconnect.com/contentone/ben/cmm/2010/ 00000010/00000003/art00011?crawler=true

Expert Panel on Detection, Evaluation, and Treatment of High Blood Cholesterol in Adults (2001) Executive Summary of The Third Report of The National Cholesterol Education Program (NCEP) Expert Panel on Detection, Evaluation, And Treatment of High Blood Cholesterol In Adults (Adult Treatment Panel III). $J A M A$ 285: 2486-2497. http://jama.jamanetwork.com/article. aspx?articleid $=193847$

Evans MD, Singh R, Mistry V, Sandhu K, Farmer PB, Cooke MS (2008) Analysis of urinary 8-oxo-7,8-dihydro-purine-2'-deoxyribonucleosides by LC-MS/MS and improved ELISA. Free Radic Res 42: 831-840. http://www.ncbi.nlm.nih.gov/pubmed/18985483

Feig D, Duk-Hee K, Johnson RH (2008) Uric Acid and Cardiovascular Risk. N Engl J Med 359: 1811-1821. http://www.ncbi.nlm.nih.gov/ pmc/articles/PMC2684330/

Halliwell B, Gutteridge JMC (2015) Reactive species can be poisonous. In Free Radical Biology and Medicine. 5th edn. Halliwell B, Gutteridge JMC eds, pp 463-510. Oxford University Press

Hayden MR, Tyagi SC (2004) Uric acid: A new look at an old risk marker for cardiovascular disease, metabolic syndrome, and type 2 diabetes mellitus: The urate redox shuttle. Nutr Metab (Lond) 1: 10. http://www.ncbi.nlm.nih.gov/pmc/articles/PMC529248/

International Diabetes Federation (2015) IDF Diabetes Atlas. 7 edn. International Diabetes federation. http://www.diabetesatlas.org.

Jackson SP, Bartek J (2009) The DNA-damage response in human biology and disease. Nature 461: 1071-1078. http://www.ncbi.nlm.nih. gov/pmc/articles/PMC2906700/

Li YS, Song MF, Kasai H, Kawai K (2013) 8-hydroxyguanine in urine and serum as an oxidative stress marker: effects of diabetes and aging. J UOEH 35: 119-127. https://www.jstage.jst.go.jp/article/ juoeh/35/2/35_119/_article

Loft S, Danielsen P, Løhr M, Jantzen K, Hemmingsen JG, Roursgaard M, Karotki DG, Møller P (2012) Urinary excretion of 8-oxo-7,8dihydroguanine as biomarker of oxidative damage to DNA. Arch Biochem Biophys 518: 142-150. http://www.ncbi.nlm.nih.gov/pub$\mathrm{med} / 22239988$

Løhr M, Jensen A, Eriksen L, Grønbæk M, Loft S, Møller P (2015). Age and metabolic risk factors associated with oxidatively damaged DNA in human peripheral blood mononuclear cells. Oncotarget 6: 2641-2653

Milić M, Kišan M, Rogulj D, Radman M, Lovrenčić MV, Konjevoda P, Domijan AM (2013) Level of primary DNA damage in the early stage of metabolic syndrome. Mutat Res Genet Toxicol Environ Mutagen 758: 1-5. http://www.ncbi.nlm.nih.gov/pubmed/24076402

Poulsen HE, Nadal LL, Broedbaek K, Nielsen PE, Weimann A (2014) Detection and interpretation of 8-oxodG and 8-oxoGua in urine, plasma and cerebrospinal fluid. Biochim Biophys Acta 1840: 801-808. http://www.ncbi.nlm.nih.gov/pubmed/23791936

Roberts CK, Sindhu KK (2009) Oxidative stress and metabolic syndrome. Life Sci 84: 705-712. http://www.ncbi.nlm.nih.gov/pubmed/19281826 
Rochette L, Zeller M, Cottin Y, Vergely C (2014) Diabetes, oxidative stress and therapeutic strategies. Bioch Biophys Acta 1840: 2709-2729. http://www.ncbi.nlm.nih.gov/pubmed/24905298

Rytter E, Vessby B, Asgård R, Johansson C, Sjödin A, AbramssonZetterberg L, Möller L, Basu S (2009) Glycaemic status in relation to oxidative stress and inflammation in well-controlled type 2 diabetes subjects. Br J Nutr 101: 1423-1426. http://www.ncbi.nlm.nih. gov/pubmed/19459227

Soares JP, Cortinhas A, Bento T, Leitão JC, Collins AR, Gaivão I, Mota MP (2014) Aging and DNA damage in humans: a meta-analysis study. Aging (Albany NY) 6: 432-439

Song F, Jia W, Yao Y (2007) Oxidative stress, antioxidant status and DNA damage in patients with impaired glucose regulation and newly diagnosed Type 2 diabetes Clin Sci (Lond) 112: 599-606. http:// www.ncbi.nlm.nih.gov/pubmed/17209802

Takahashi S, Yamamoto T, Tsutsumi Z, Moriwaki Y, Yamakita J, Higashino K (1997) Close correlation between visceral fat accumula- tion and uric acid metabolism in healthy men. Metabolism 46: 1162 1165. http://www.ncbi.nlm.nih.gov/pubmed/9322800

Valko M, Leibfritz D, Moncol J, Cronin TDM, Mazur M, Telser J (2007) Free radicals and antioxidants in normal physiological functions and human disease. Int J Biochem Cell Biol 39: 44-84. http:// www.ncbi.nlm.nih.gov/pubmed/16978905

Vučić Lovrenčić M, Pibernik-Okanović M, Šekerija M, Prašek M, Ajduković D, Kos J, Hermanns N (2015) Improvement in depressive symptoms is associated with reduced oxidative damage and inflammatory response in type 2 diabetic patients with subsyndromal depression: the results of a randomized controlled trial comparing psychoeducation, physical exercise, and enhanced treatment as usual. J Endocrinol Diabetes 210406. http://www.hindawi.com/journals/ ije/2015/210406/ 